University of Zurich

Department of Economics

Working Paper Series

ISSN 1664-7041 (print)

ISSN 1664-705X (online)

Working Paper No. 259

\title{
Money, Banking and Financial Markets
}

David Andolfatto, Aleksander Berentsen and Fernando M. Martin

August 2017 


\title{
Money, Banking and Financial Markets*
}

\author{
David Andolfatto \\ Federal Reserve Bank of St. Louis and Simon Fraser University \\ Aleksander Berentsen \\ Fernando M. Martin \\ University of Basel \\ Federal Reserve Bank of St. Louis
}

August 3, 2017

\begin{abstract}
The fact that money, banking, and financial markets interact in important ways seems self-evident. The theoretical nature of this interaction, however, has not been fully explored. To this end, we integrate the Diamond (1997) model of banking and financial markets with the Lagos and Wright (2005) dynamic model of monetary exchange-a union that bears a framework in which fractional reserve banks emerge in equilibrium, where bank assets are funded with liabilities made demandable for government money, where the terms of bank deposit contracts are constrained by the liquidity insurance available in financial markets, where banks are subject to runs, and where a central bank has a meaningful role to play, both in terms of inflation policy and as a lender of last resort. The model provides a rationale for nominal deposit contracts combined with a central bank lender-of-last-resort facility to promote efficient liquidity insurance and a panic-free banking system.
\end{abstract}

The views expressed in this paper do not necessarily reflect official positions of the Federal Reserve Bank of St. Louis, the Federal Reserve System, or the Board of Governors.

${ }^{*}$ We thank Rodi Manuelli, Guillaume Plantin, Jean-Charles Rochet, Mariana Rojas Breu, Christopher Waller, Steve Williamson, Randy Wright and many seminar participants for several very useful comments and criticisms. 


\section{Introduction}

The fact that money, banking, and financial markets interact in important ways seems selfevident. The theoretical nature of this interaction, however, has not been fully explored. Diamond and Dybvig (1983), for example, explain the existence of banking, but do so in a model without money or financial markets. Diamond (1997) explains how banks and financial markets compete as mechanisms for liquidity insurance, but does so in a model without money. Loewy (1991) develops a model with money and banking, but abstracts from monetary policy and financial markets. Smith (2002) presents a model of money, banking, and monetary policy, but abstracts from financial markets. As far as we know, there has been no comprehensive theoretical analysis of how these three factors interact with each other. Of course, it is not possible to know a priori what, if anything, is lost by the absence of a such a model. The present paper constitutes an attempt to find out.

To this end, we combine the Diamond (1997) model of banking and financial markets with the Lagos and Wright (2005) model of monetary exchange. The result is a model where fractional reserve banks emerge in equilibrium, where bank assets are funded with liabilities made demandable for government money, where the terms of bank deposit contracts are constrained by the liquidity insurance available in financial markets, where banks are subject to runs, and where a central bank has a meaningful role to play, both in terms of inflation policy and as a lender of last resort.

In our model, money takes the form of zero-interest nominal government debt. The real rate of return on money-the inverse of the inflation rate-is determined by policy and is financed with lump-sum taxes or transfers. Money is necessary in the economy because an absence of trust between some trading parties precludes the use of credit (Gale, 1978). Money, however, is dominated in rate of return by securities representing claims against an income-generating capital good. Securities are illiquid in the sense they cannot be used to make some payments. But securities possess a degree of liquidity indexed by the ease with which they can be exchanged for money on short notice. A financial market in which securities trade for money provides one mechanism for investors to access liquid funds. A bank that stands ready to convert deposit liabilities for cash provides another such mechanism.

Following Allen and Gale (2007, § 3.2), our investigation begins by asking how the economy might function in the absence of banks, but where investors have access to a market where they can liquidate securities. A well-known conclusion in this body of literature is that the resulting competitive equilibrium is inefficient, except for a knife-edge case relating to the nature of preferences (see also Farhi, Golosov, and Tsyvinski, 2009). We find that this conclusion is an artifact of the static nature of the models employed. Our first result demonstrates that if monetary policy follows the Friedman rule, then the competitive equilibrium of an economy with a securities markets is efficient and that, moreover, the ability to save money across time is critical for this to be true. The economic rationale for a banking system in this environment must therefore stem from one of two frictions, either: (i) monetary policy departs from the Friedman rule and/or (ii) the requisite securities market is either absent or sufficiently palsied. 
Next, we examine how the economy might function in the absence of a securities market, so that cash and securities are held indirectly as bank deposit liabilities. As in Diamond and Dybvig (1983), the optimal risk-sharing arrangement entails demandable debt, except that in our case, this debt is made redeemable for government money (instead of goods). We find that a competitive (or monopolistic, but contestable) banking system is also consistent with efficiency, but once again, only when monetary policy follows the Friedman rule. Thus, the choice of banks vs. securities markets is inconsequential when inflation policy is set optimally.

Away from the Friedman rule, the return on money is too low and thus, liquidity is scarce in both financial markets and banking systems. However, inflation impacts both these systems differently. In financial markets, inflation also taxes any excess money investors would like to carry across periods - as argued above, these savings are necessary for firstbest implementation. In contrast, banks do not hold any excess cash and are thus not subject to this additional inefficiency. ${ }^{1}$

As alluded to above, Diamond and Dybvig (1983) assume that depositors are prevented from engaging in financial transactions outside of their banking relationship. Bencivenga and Smith (1991) suggest that this is approximately true in developing economies where government legislation and regulation often serves to repress financial markets in favor of banks. But in more advanced economies, securities markets are relatively well-developed so that depositors have more options. It has been known since at least Jacklin (1987) that if depositors cannot be refrained from engaging in ex post financial market trades, the ex ante superior liquidity insurance made possible through banks may not emerge in equilibrium. Indeed, we reproduce the Jacklin (1987) result: if depositors have free and easy access to an ex post securities market, banks are essentially constrained to offer a liquidity insurance contract that replicates what would be offered in a competitive financial market. Our monetary model shows that the resulting welfare loss from "excess competition" in this form is increasing in the rate of inflation.

Of course, even in more advanced economies, access to securities markets is not costless so that participation is limited. Following Diamond (1997), we introduce a parameter that governs how easily investors can access the securities market. At one extreme, securities are completely illiquid-the standard Diamond and Dybvig (1983) assumption. At the other extreme, securities are perfectly liquid-the Allen and Gale $(2007, \S 3.2)$ assumption. We find that the Friedman rule implements the efficient allocation independent of the degree of securities market liquidity. The existence of banks is critical for this result, as in their absence investors that cannot gain timely access to a securities market would be forced to liquidate their investments in some less efficient manner. Away from the Friedman rule, financial market innovations that render securities markets more liquid cut into the banking sector's ability to provide liquidity insurance. Hence, banks become more efficient as securities market liquidity is impaired. The welfare loss from greater securities market liquidity vanishes as inflation policy approaches the Friedman rule.

\footnotetext{
${ }^{1}$ This result supports the argument put forth by Diamond (1997) that banks improve the allocation by centralizing the holding of short-term liquidity — which reduces the opportunity cost of holding liquid assets. In contrast, in the equilibrium with financial markets, for a low enough inflation rate, investors hold idle liquidity by saving money across periods.
} 
The results reported to this point rest on the assumption that banks are not subject to bank panics (or bank runs). Panics refer to events in which banks fall into insolvency owing to a fear of insolvency that becomes a self-fulfilling prophecy. Of course, the Diamond and Dybvig (1983) model was motivated by the question of whether the banking system is prone to panics and whether a government deposit insurance scheme could be designed to eliminate them. However, as far as we know, the question of how the presence of a securities market interacts with the phenomenon of bank panics in the Diamond and Dybvig (1983) framework has not been investigated. Our results here are summarized as follows.

In the case of a perfectly liquid securities market, banks cannot improve the market allocation and so, if banks did exist, the welfare consequences of a bank panic are inconsequential as depositors are in a position to liquidate their securities at non-distressed market prices. The downside to liquid securities markets is that risk-sharing is relatively poor. In the case of an illiquid securities market, banks provide superior risk-sharing, but are vulnerable to panics. In the event of a panic, early liquidation of banks' assets leads to financial losses for all depositors. Those without market access are further harmed by holding an improper portfolio mix, which they are now unable to rebalance according to their needs.

Thus, we identify what we think is an interesting trade-off. Innovations designed to improve securities market liquidity lead to less risk-sharing, but conditional on a bank panic lead to better ex post liquidation outcomes. Conversely, restrictions on the trading of securities improve liquidity insurance, but leave the economy vulnerable to the dislocations associated with banking panics. The trade-off between insurance and stability is shown to depend on the how bankruptcy is resolved. Our model suggests that dispersing assets in the form of cash and "clearinghouse certificates" generally dominates asset liquidation.

The trade-off between liquidity insurance and bank-panic resiliency vanishes under an appropriate and more comprehensive monetary policy. The source of instability in the Diamond and Dybvig (1983) model is a contractual incompleteness that renders bank deposit liabilities "run-prone". ${ }^{2}$ In principle, a fiscal policy that insures deposits against such events could prevent panics from occurring. But the effectiveness of an intervention depends on its credibility and a fiscal intervention must ultimately resort to direct taxation. Relative to fiscal policy, monetary policy has a distinct advantage because the object under its control (cash) also happens to be the object of redemption in demand deposit contracts. Thus, if deposit liabilities are purposely designed to be claims against cash (instead of goods), the monetary authority is always in a position to print the cash necessary to help banks fulfill their nominal obligations. The fact that cash can be printed costlessly greatly enhances the credibility of the intervention and, in this way, the threat of such an intervention is sufficiently credible to discourage bank panics.

The paper is organized as follows. In Section 2, we describe the physical properties of the model economy and characterize the nature of an efficient allocation. In Section 3, we introduce the frictions that motivate monetary exchange and we characterize the competitive equilibrium with a securities market, but absent banking and a banking equilibrium,

\footnotetext{
${ }^{2}$ In particular, if promised redemption rates are made invariant to the volume of early withdrawals, a wave of heavy redemption activity may leave a bank (or the banking system) without enough cash to fulfil its obligations. If the fear of such an event leads depositors to withdraw cash en masse, the result is a self-fulfilling bank panic.
} 
absent a securities market. In section 4, we examine how banks are affected when they must compete with a securities market for the provision of liquidity insurance. Section 5 examiness the interaction between bank panics and the degree of securities market liquidity. In Section 6, we discuss the merits of a central bank lending facility and the benefits of nominal debt. Section 7 concludes.

\section{The environment}

Time, denoted $t$, is discrete and the horizon is infinite, $t=0,1,2, \ldots, \infty$. Each time period $t$ is divided into three subperiods: the morning, afternoon and evening. There are two permanent types of agents, each of unit measure, which we label investors and workers.

Investors can produce morning output $y_{0}$ at utility cost $-y_{0}$. This output can be divided into consumer $(x)$ and capital $(k)$ goods, so that $y_{0}=x+k$. Investors are subject to an idiosyncratic preference shock, realized at the beginning of the afternoon, which determines whether they prefer to consume early (in the afternoon) or later (in the evening). Let $0<\pi<1$ denote the probability that an investor desires early consumption $c_{1}$ (the investor is impatient). The investor desires late consumption $c_{2}$ (the investor is patient) with probability $1-\pi$. There is no aggregate uncertainty over investor types so that $\pi$ also represents the fraction of investors who desire early consumption. The utility payoffs associated with early and late consumption are given by $u\left(c_{1}\right)$ and $u\left(c_{2}\right)$, respectively, where $u^{\prime \prime}<0<u^{\prime}$ with $u^{\prime}(0)=\infty$. Investors discount utility payoffs across periods with subjective discount factor $0<\beta<1$, so that investor preferences are given by

$$
E_{0} \sum_{t=0}^{\infty} \beta^{t}\left[-y_{0, t}+\pi u\left(c_{1, t}\right)+(1-\pi) u\left(c_{2, t}\right)\right]
$$

Workers have linear preferences defined over morning and afternoon goods. In particular, workers wish to consume in the morning $c_{0}$ and have the ability to produce goods in the afternoon $y_{1}$. Goods produced in the afternoon can be stored into the evening of the same period, but are perishable across periods. Workers share the same discount factor as investors, so that worker preferences are given by

$$
E_{0} \sum_{t=0}^{\infty} \beta^{t}\left[c_{0, t}-y_{1, t}\right]
$$

The investment technology available to investors works as in the manner described in Cooper and Ross (1998). In particular, capital goods produced in the morning $(k)$ are assumed to generate a high rate of return $(R>1)$ if left to gestate into the evening and a low rate of return $(0<r<1)$ if gestation is interrupted and operated in the afternoon. ${ }^{3}$ For simplicity, we assume that capital depreciates fully after it is used in evening production.

To characterize an efficient allocation, consider the problem of maximizing the ex ante welfare of investors, subject to delivering workers an expected utility payoff no less than a

\footnotetext{
${ }^{3}$ Note that Diamond and Dybvig (1983) assume $r=1$.
} 
given number (normalized here to zero, so that $c_{0}=y_{1}$ ). The condition $r<1$ implies that workers can supply afternoon output more efficiently than investors who operate capital prematurely in the afternoon. As a consequence, efficiency dictates that premature capital utilization is never optimal. We anticipate that the resource constraint $x=c_{0}$ must hold since the morning transfer of utility from investors to workers must balance. With these conditions imposed, the planning problem may be written as

$$
\max \left\{-x-k+\pi u\left(c_{1}\right)+(1-\pi) u\left(c_{2}\right)\right\}
$$

subject to

$$
\begin{aligned}
x-\pi c_{1} & \geq 0 \\
R k+\left[x-\pi c_{1}\right]-(1-\pi) c_{2} & \geq 0
\end{aligned}
$$

The first-best allocation is characterized by the following two restrictions,

$$
u^{\prime}\left(c_{1}^{*}\right)=R u^{\prime}\left(c_{2}^{*}\right)=1
$$

where, using (4) and (5), $x^{*}=\pi c_{1}^{*}$ and $k^{*}=(1-\pi) c_{2}^{*} / R$. For the special case $u^{\prime}(c)=c^{-\sigma}$, $\sigma>0$, we have,

$$
c_{1}^{*}=1 \text { and } c_{2}^{*}=R^{1 / \sigma}
$$

If, in addition, investor types are private information, then incentive-compatibility (IC) conditions are necessary to ensure truthful revelation. For patient investors, IC requires $c_{2} \geq c_{1}$ and for impatient investors, IC requires $c_{1} \geq 0$. Note that (6) implies that $c_{2}^{*}>$ $c_{1}^{*}>0$, so that the first-best allocation is incentive-compatible. Note too that conditions (6) imply $u^{\prime}\left(c_{1}^{*}\right)=R u^{\prime}\left(c_{2}^{*}\right)$ as in the standard Diamond-Dybvig model. However, unlike the standard model, ours is a production economy with linear costs, which is why both $u^{\prime}\left(c_{1}^{*}\right)$ and $R u^{\prime}\left(c_{2}^{*}\right)$ need to equal the constant marginal cost of production at the first-best.

\section{Competitive monetary equilibrium}

Workers and investors meet in the morning and in the afternoon (but not in the evening). Ideally, investors would like to borrow output from workers in the afternoon, repaying the loan in the next morning. Such credit arrangements are ruled out here because workers and investors are assumed not to trust each other (Gale, 1978). As a consequence, any trade between workers and investors must occur on a quid-pro-quo basis through the use of an exchange medium. The exchange medium here is assumed to take the form of a zerointerest-bearing government debt instrument (money), the total nominal supply of which is denoted $M_{t}$ at the beginning of date $t$.

Assume that the initial money supply $M_{0}>0$ is owned entirely by workers (this initial condition is immaterial for what follows). New money is created at the beginning of each morning at the constant rate $\mu$, so that $M_{t}=\mu M_{t-1}$. We assume that new money $T_{t}=$ 
$(1-1 / \mu) M_{t}$ is injected as lump-sum transfers to workers. ${ }^{4}$ Because preferences are (quasi) linear, the positive implications of our analysis are unaffected by precisely who gets the new money although, of course, there are redistributional consequences. Exchange between workers and investors takes place on a sequence of competitive spot markets. We assume that trade in goods (for money) occur on a sequence of competitive spot markets. Let $\left(p_{t}^{m}, p_{t}^{a}\right)$ denote the dollar price of output in the morning and afternoon, respectively.

Workers produce output in the afternoon for money, and carry the money forward to the next morning where they spend it on consumption. Because workers have linear preferences, their cost-benefit calculation is simple to characterize. To acquire a dollar in the afternoon, a worker must expend $1 / p_{t}^{a}$ units of labor. This dollar is convertible for $1 / p_{t+1}^{m}$ units of output the following morning. In present value terms, this future output is worth $\beta / p_{t+1}^{m}$ units of afternoon $t$ output. For an arbitrary price-system, the solution is at one of two corners: workers will want to work as much as possible, or not at all. But we anticipate that the following condition will have to hold in equilibrium,

$$
1 / p_{t}^{a}=\beta / p_{t+1}^{m}
$$

Condition (8) implies that workers are willing to supply output passively (elastically) in the afternoon to accommodate any level of investor demand.

Before describing the behavior of investors, it will prove useful to anticipate an equilibrium condition. In a stationary equilibrium, we know that all nominal prices will grow at the same rate as the money supply. That is,

$$
p_{t+1}^{m} / p_{t}^{m}=p_{t+1}^{a} / p_{t}^{a}=\mu
$$

Combining this latter restriction with condition (8) implies,

$$
p_{t}^{m} / p_{t}^{a}=\beta / \mu
$$

Condition (10) says that when monetary policy is away from the Friedman rule (i.e., $\beta<\mu$ ), the price of afternoon money is discounted relative to morning money, i.e., $1 / p_{t}^{a}<1 / p_{t}^{m}$. This is because money acquired in the afternoon can only be spent the next day and, away from the Friedman rule, money earns less than its socially optimal rate of return.

Condition (10) expresses the real rate of return to money held from the morning to afternoon. The return to capital goods held over the same period is $r$. In what follows, we assume that $(\beta / \mu)>r$ so that money is preferred to capital goods as a "short-run" investment vehicle. We also assume that $\mu \geq \beta$, since monetary equilibria otherwise fail to exist. To summarize, throughout the remainder of the paper we assume,

[A1] $r<\beta / \mu<1$.

\footnotetext{
${ }^{4}$ While we permit any amount of deflation here in the range $\beta \leq \mu<1$, there is the question of whether lump-sum taxation is an incentive-feasible policy. Andolfatto (2013) addresses this issue, but we ignore it in what follows. Note that assuming new money is distributed to workers only is made for expositional clarity (see Appendix B for how to map the general case into our results).
} 
Money here substitutes for a missing credit market, but does not substitute for the missing insurance market. Because $R>1$, capital goods (or claims to capitals goods, which we call securities) are preferred to money as a "long-run" investment vehicle. But the willingness of investors to hold securities will depend in part on how easily they can be liquidated (convertible to cash) in the random event they become impatient. This, in turn, depends on the availability of a securities market, or some institution (like a bank) that stands ready to perform the conversion. In what follows, we study the role of securities markets and a banking system as alternative mechanisms for providing the desired liquidity insurance.

\subsection{A securities market}

In this section, we follow Diamond (1997) and Allen and Gale $(2007, \S 3.2)$ in first examining how this economy might solve the "liquidity problem" through the use of a competitive securities market where investors can exchange securities for money in the afternoon after their preference types have been realized. Let $q_{t}$ denote the nominal price of a security (a claim to a unit of the capital good, measured in units of money).

Since capital goods depreciate fully at the end of each period, investors will enter the morning with zero securities and $m_{t}^{m} \geq 0$ units of money. In the morning investors will want to rebuild their depleted wealth portfolios. They can do so in two ways, first, by working to produce consumer goods in exchange for money and second, by working to produce new capital goods. Define real money balances at the beginning of the morning $z \equiv m_{t}^{m} / p_{t}^{m}$ and real money balances after morning trading by $x \equiv m_{t}^{a} / p_{t}^{m} \cdot{ }^{5}$

In the afternoon, investors learn whether they are patient or impatient. We anticipate that impatient investors will want to sell securities and that patient investors will want to buy them. Let $k_{1}$ and $k_{2}$ denote the securities bought and sold, by an impatient and patient investor, respectively. An impatient investor faces the constraint $k \geq k_{1}$ while a patient agent faces the constraint $m_{t}^{a} \geq q_{t} k_{2}$.

Using the fact that $x=m_{t}^{a} / p_{t}^{m}$, the real value of money balances in the afternoon is given by $m_{t}^{a} / p_{t}^{a}=\left(p_{t}^{m} / p_{t}^{a}\right) x$. Using condition $(10)$, we can write $m_{t}^{a} / p_{t}^{a}=(\beta / \mu) x$. It will also prove useful to define $\rho \equiv q_{t} / p_{t}^{a}$, the afternoon price of capital goods measured in units of afternoon output. All investors carry their morning wealth $x+k$ into the afternoon, where it is worth $(\beta / \mu) x+\rho k$, measured in units of afternoon output. Let $m_{1, t+1}^{m}, m_{2, t+1}^{m} \geq 0$ denote the money carried forward to the next morning for the impatient and patient investor, respectively. Using (8) and the fact that (in a stationary equilibrium) $\mu=p_{t+1}^{m} / p_{t}^{m}$, we have $m_{i, t+1}^{m} / p_{t}^{a}=\beta z_{i}^{+}$for $i=1,2$.

Now consider the budget equation for an impatient investor, $c_{1}+m_{1, t+1}^{m} / p_{t}^{a}=m_{t}^{a} / p_{t}^{a}+$ $\left(q_{t} / p_{t}^{a}\right) k_{1}+r\left(k-k_{1}\right)$. Using the notation developed above, rewrite this equation as

$$
c_{1}=(\beta / \mu) x+\rho k_{1}+r\left(k-k_{1}\right)-\beta z_{1}^{+}
$$

\footnotetext{
${ }^{5}$ Note that, from this point on, we drop the time script notation for real variables. A contemporaneous variable $x_{t}$ is simply denoted $x$ and a future variable $x_{t+1}$ is denoted $x^{+}$.
} 
The impatient investor is subject to the following constraints,

$$
\begin{aligned}
z_{1}^{+} & \geq 0 \\
k-k_{1} & \geq 0 \\
(\beta / \mu) x+\rho k_{1}-\beta z_{1}^{+} & \geq 0
\end{aligned}
$$

Condition (12) says that cash balances carried forward in time cannot be negative (there is no borrowing). Condition (13) says that the impatient investor cannot sell more capital goods in the afternoon securities market than he brings into the period. Condition (14) says that the amount of cash brought into the next period cannot exceed the amount of cash brought into the afternoon augmented by the cash acquired via afternoon sales of capital goods.

Next, consider the budget equation for a patient investor, $c_{2}+m_{2, t+1}^{m} / p_{t}^{a}=R\left(k+k^{P}\right)+$ $m_{t}^{a} / p_{t}^{a}-\left(q_{t} / p_{t}^{a}\right) k_{2}$. Again, using the notation developed above, rewrite this budget equation as

$$
c_{2}=R\left(k+k_{2}\right)+(\beta / \mu) x-\rho k_{2}-\beta z_{2}^{+}
$$

The patient investor is subject to the following constraints,

$$
\begin{aligned}
z_{2}^{+} & \geq 0 \\
(\beta / \mu) x-\rho k_{2} & \geq 0 \\
(\beta / \mu) x-\rho k_{2}-\beta z_{2}^{+} & \geq 0
\end{aligned}
$$

Condition (16) stipulates that cash balances going forward must be non-negative. Condition (17) states that the value of capital goods purchased in the securities market cannot exceed the amount of cash on hand. Condition (18) says that the amount of cash carried forward plus cash spent on securities cannot exceed the amount of cash on hand.

As it turns out, constraints (14) and (17) are redundant and hence, can me omitted from the investor's problem.

Lemma 1 The inequality constraints (14) and (17) do not bind.

Let $V(z)$ denote the value function associated with real money balances $z$ in the morning. This value function must satisfy the following recursive relationship,

$$
V(z) \equiv \max _{x, k, k_{1}, k_{2}, z_{1}^{+}, z_{2}^{+}} z-x-k+\pi\left[u\left(c_{1}\right)+\beta V\left(z_{1}^{+}\right)\right]+(1-\pi)\left[u\left(c_{2}\right)+\beta V\left(z_{2}^{+}\right)\right]
$$

subject to (12), (13), (16) and (18), and where $c_{1}$ and $c_{2}$ are given by (11) and (15), respectively.

Let $\pi \beta \zeta_{1}$ and $(1-\pi) \beta \zeta_{2}$ denote the Lagrange multipliers associated with the nonnegativity constraints (12) and (16), respectively. Let $\pi \lambda_{1}$ and $(1-\pi) \lambda_{2}$ denote the Lagrange multipliers associated with the constraints (13) and (18), respectively. In what follows, we 
assume (and later verify) that $x>0$ and $k>0$. After some simple rearrangements the first-order necessary conditions for an optimum imply

$$
\begin{aligned}
\pi u^{\prime}\left(c_{1}\right)+(1-\pi)(R / \rho) u^{\prime}\left(c_{2}\right) & =\mu / \beta \\
\pi u^{\prime}\left(c_{1}\right)+(1-\pi)(R / \rho) u^{\prime}\left(c_{2}\right) & =1 / \rho \\
(\rho-r) u^{\prime}\left(c_{1}\right) & =\lambda_{1} \\
(R / \rho-1) u^{\prime}\left(c_{2}\right) & =\lambda_{2} \\
u^{\prime}\left(c_{1}\right)-1 & =\zeta_{1} \\
(R / \rho) u^{\prime}\left(c_{2}\right)-1 & =\zeta_{2}
\end{aligned}
$$

Conditions (20) and (21) imply that the equilibrium price of capital goods in the afternoon securities market is pinned down by monetary policy, i.e.,

$$
\rho=\beta / \mu
$$

At the individual level, investors are indifferent between holding money or capital goods in their wealth portfolios because the short-run rate of return on money and capital goods is equated, in equilibrium, through a no-arbitrage-condition.

It is worthwhile to think through the intuition that governs the no-arbitrage-condition (26). Suppose that $\rho>\beta / \mu$. In this case, investors have no incentive to accumulate money in the morning because in the event they need money, they expect to be able to liquidate securities for a higher rate of return. Collectively, this means that the demand for real money balances goes to zero, which cannot be a part of any monetary equilibrium. ${ }^{6}$ Suppose, alternatively, that $\rho<\beta / \mu$. In this case, investors would prefer to accumulate only money in the morning because in the event they want securities (because they turn out to be patient), they expect to purchase these securities cheaply. However, because securities would in this case be absent, their price would be infinite-a contradiction.

Securities market-clearing in our model implies,

$$
\pi k_{1}=(1-\pi) k_{2}
$$

Note that, given [A1] and (26), conditions (22)-(23) imply $\lambda_{1}>0$ and $\lambda_{2}>0$, respectively. That is, constraints (13) and (18) bind. Thus, $k_{1}=k$ which, when combined with (27), implies $k_{2}=\pi(1-\pi)^{-1} k$, and $(\beta / \mu) x=\rho k_{2}+\beta z_{2}^{+}$. Thus, (15) implies

$$
c_{2}=R k /(1-\pi)
$$

Because capital goods depreciate fully at the end of the evening, securities issued in the morning are fully redeemed in the evening. Furthermore, patient investors use their cash holdings to either purchase securities in the afternoon or to save on effort in the following morning. Recall that any cash on hand in the evening cannot be spent because by assumption investors are not in communication with workers in the evening. It therefore follows that evening consumption is financed entirely through securities redemptions.

\footnotetext{
${ }^{6}$ Of course, $x=0$ is consistent with a non-monetary equilibrium, which exists in every monetary model.
} 
Since constraint (18) binds, $(\beta / \mu) x-\rho k_{2}=\beta z_{2}^{+}$. Use $(26)$ and $k_{2}=\pi(1-\pi)^{-1} k$ to rewrite this condition as

$$
\mu z_{2}^{+}=x-\pi(1-\pi)^{-1} k
$$

[A2] $u^{\prime}(c) c$ is strictly decreasing in $c$.

Under assumption [A2], when monetary policy is away from the Friedman rule, i.e., $\mu>\beta$, impatient investors will never choose to carry money across periods; i.e., $\zeta_{1}>0$ $\left(z_{1}^{+}=0\right)$. At the Friedman rule, we can set $z_{1}^{+}=0$ without loss of generality.

Lemma 2 Assume [A1] and [A2]. Then, $z_{1}^{+}=0$.

In the proof of Lemma 2 we also consider the case when [A2] is not satisfied. Combine the fact that $z_{1}^{+}=0, k_{1}=k, \rho=\beta / \mu$ with (11) to derive

$$
c_{1}=(\beta / \mu)(x+k)
$$

Finally, use (21) and (26) to form,

$$
\pi(\beta / \mu) u^{\prime}\left(c_{1}\right)+(1-\pi) R u^{\prime}\left(c_{2}\right)=1
$$

There will be two cases to consider depending on whether $z_{2}^{+}=0$ or $z_{2}^{+}>0$. Assume for the moment that $z_{2}^{+}=0$ (we will later describe a region in the parameter space where this assumption is valid). In this case, conditions (29) and (30) imply $k=(\mu / \beta)(1-\pi) c_{1}$ which, when combined with Lemma 2 , results in the condition

$$
c_{2}=R(\mu / \beta) c_{1}
$$

Conditions (31) and (32) characterize the equilibrium allocation $\left(c_{1}, c_{2}\right)$ when investors choose to carry no cash across periods. This case corresponds closely to the static models studied by Diamond (1997) and Allen and Gale (2007, § 3.2) except that in our case, zero saving is derived as a property of the equilibrium in some cases, rather than assumed to hold at all times.

Consider next the case for which $z_{2}^{+}>0$. Because $\zeta_{2}=0$, condition (25) and (26) imply that $c_{2}$ is characterized by

$$
R u^{\prime}\left(c_{2}\right)=\beta / \mu
$$

Thus, conditions (31) and (33) characterize the equilibrium allocation $\left(c_{1}, c_{2}\right)$ for the case in which a patient investor desires to carry cash over time.

While it is possible to proceed in a slightly more general manner, in what follows we restrict ourselves to a class of utility functions that permit a closed-form solution. In particular, assume the following:

[A3] $u^{\prime}(c)=c^{-\sigma}$, where $\sigma>1$. 
Note that condition [A3] implies that condition [A2] holds as well. For the case $z_{2}^{+}=0$, we need to verify that condition (25) holds with $\zeta_{2}>0$, that is $(R / \rho) c_{2}^{-\sigma}>1$. Using (32), this latter condition can be expressed as $(R / \rho)^{1-\sigma} c_{1}^{-\sigma}>1$. Now use (31) and (32) to solve for $c_{1}^{-\sigma}=\left[\pi \rho+(1-\pi) R^{1-\sigma} \rho^{\sigma}\right]^{-1}$. Thus, the necessary condition is given by,

$$
(R / \rho)^{1-\sigma}>\pi \rho+(1-\pi) R^{1-\sigma} \rho^{\sigma}
$$

Condition (34) will of course hold for a wide range of parameters. But there are also regions in the parameter space where it does not hold. For the special case $\sigma=2$, (34) implies that the inflation rate $\mu$ needs to exceed a critical value $\mu_{0}>\beta$, i.e.,

$$
\mu>\left(\frac{1-\pi}{1-\pi R}\right) \beta \equiv \mu_{0}>\beta
$$

Thus, patient investors dispose of all their cash holdings in the afternoon securities market only if the inflation rate is sufficiently high $\left(\mu>\mu_{0}>\beta\right)$. Otherwise, they are willing to carry cash over time even if monetary policy operates away from the Friedman rule, at least, as long as inflation is sufficiently low $\left(\mu_{0}>\mu>\beta\right)$.

Let $\left(c_{1}^{D}, c_{2}^{D}\right)$ denote the equilibrium allocation assuming [A1] and [A3]. Using the restrictions deduced above, we have

$$
\begin{aligned}
& c_{1}^{D}=\left\{\begin{array}{lll}
(\pi \rho)^{1 / \sigma}[1-(1-\pi) \rho]^{-1 / \sigma} & \text { if } & \mu<\mu_{0} \\
{\left[\pi \rho+(1-\pi) R^{1-\sigma} \rho^{\sigma}\right]^{1 / \sigma}} & \text { if } & \mu \geq \mu_{0}
\end{array}\right. \\
& c_{2}^{D}=\left\{\begin{array}{lll}
(R / \rho)^{1 / \sigma} & \text { if } & \mu<\mu_{0} \\
{\left[\pi R^{\sigma} \rho^{1-\sigma}+(1-\pi) R\right]^{1 / \sigma}} & \text { if } & \mu \geq \mu_{0}
\end{array}\right.
\end{aligned}
$$

where $\rho=\beta / \mu$.

Proposition 1 Assume [A1] and [A3]. The equilibrium allocation in the securities market economy possesses the following properties: (i) $c_{1}^{D}(\mu)<c_{1}^{*}$ and is strictly decreasing in $\mu$, with $c_{1}^{D}(\beta)=c_{1}^{*}$; (ii) $c_{2}^{D}(\mu)>c_{2}^{*}$ and is strictly increasing in $\mu$, with $c_{2}^{D}(\beta)=c_{2}^{*}$.

Proposition 1 asserts that inflation harms risk-sharing. Evidently, securities markets are less able to provide liquidity insurance in high-inflation environments. Why is this the case? One might think that higher inflation induces investors to economize on their morning cash balances $x$. While there is a force present (a substitution effect) that works in this direction, there is an offsetting wealth effect which induces investors to accumulate more real balances $x$ to compensate for the lower real rate of return money earns when inflation is high. For our parameterization, the net effect of higher inflation is to increase $x$ and to reduce $c_{1}$ (the increase in morning cash reserves does not fully offset the loss of purchasing power for money). Thus, inflation acts as tax on afternoon production. However, since $x=c_{0}$, it serves to stimulate morning production. Moreover, a higher rate of inflation induces an increase in evening production, $c_{2}$. This latter effect can be understood as a form of the Tobin-effect (Tobin, 1965), where higher inflation induces substitution out of cash-goods into capital formation. 


\subsubsection{The role of savings}

It is of some interest to compare our results with Allen and Gale (2007, §3.2) who report that the market mechanism studied here implements the first-best only in the special case of logarithmic utility. Our Proposition 1, in contrast, asserts that a market mechanism implements the first-best allocation for a broader class of preferences, so long as monetary policy is set optimally.

The discrepancy in these results can be traced to the fact that our model is explicitly dynamic. Allen and Gale $(2007, \S 3.2)$, in contrast, use a version of the original Diamond and Dybvig (1983) model, which is static in nature. In our model, when the return on the short asset is equal to its social optimal level (in Allen and Gale, the short-rate return is given technologically), patient investors want to save across periods. In Allen and Gale $(2007, \S 3.2)$, they are not permitted to do so. The equivalent restriction in our model would be to require $z_{1}^{+}=z_{2}^{+}=0$ always. In this case, the allocation described in (36) and (37) for $\mu \geq \mu_{0}$ would now hold for the entire range of $\mu \geq \beta$, in particular,

$$
\begin{aligned}
& c_{1}^{D}=\left[\pi \rho+(1-\pi) R^{1-\sigma} \rho^{\sigma}\right]^{1 / \sigma} \\
& c_{2}^{D}=\left[\pi R^{\sigma} \rho^{1-\sigma}+(1-\pi) R\right]^{1 / \sigma}
\end{aligned}
$$

At the Friedman rule, $\rho=1$, so that

$$
\begin{aligned}
& c_{1}^{D}=\left[\pi+(1-\pi) R^{1-\sigma}\right]^{1 / \sigma} \\
& c_{2}^{D}=\left[\pi R^{\sigma}+(1-\pi) R\right]^{1 / \sigma}
\end{aligned}
$$

In this case, $\left(c_{1}^{D}, c_{2}^{D}\right)=\left(c_{1}^{*}, c_{2}^{*}\right)=(1, R)$ iff $\sigma=1$. However, as our analysis makes clear, this result seems to have less to do with the nature of preferences and more to do with an implicit restriction on saving behavior.

Proposition 1 is important because it implicitly contains the conditions necessary to obviate a role for banking in the Diamond and Dybvig (1983) model. The first condition is that monetary policy corresponds to the Friedman rule. The second condition is the availability of a freely-available competitive securities market that permits the orderly liquidation of securities. If either or both of these conditions do not hold, then the emergence of a bank-like institution to improve risk-sharing is likely to emerge.

\section{$3.2 \quad$ A banking arrangement}

In the model described above, monetary trade with a securities market does not implement efficient risk-sharing when monetary policy operates away from the Friedman rule. When this is the case, a Diamond and Dybvig (1983) style bank that replaces the securities market may provide a superior risk-sharing arrangement. We now investigate this possibility.

A bank is an intermediary that offers investors a contract $\left(y, c_{1}, c_{2}\right)$, where $y$ denotes an investor's initial (morning) deposit and $\left(c_{1}, c_{2}\right)$ denote history-dependent withdrawal limits for the afternoon and evening, respectively. Investors participating in a banking arrangement are henceforth labeled depositors. Because depositor type is private information, the 
liabilities issued by the bank will have to be made demandable (the early withdrawal option must be made exercisable at depositor discretion). Because depositors wanting to withdraw early will want cash, the bank must hold cash reserves for the afternoon trading period. To acquire cash, the bank sells $x \leq y$ units of (claims to) morning output (to workers in the form of consumer goods) in exchange for $m_{t}^{a}=p_{t}^{m} x$ dollars of cash to be carried as reserves into the afternoon. ${ }^{7}$ The remaining claims to morning output $k=y-x$ are used to purchase income-generating capital goods. ${ }^{8}$

Thus, a bank effectively takes deposits $y$ in the morning which it divides between cash $x$ and physical capital $k$, i.e., $y=x+k$. The liabilities issued against these assets are assumed to be perfectly enforceable. Deposit liabilities not redeemed in the afternoon constitute pro rata claims against a bank's remaining assets (any residual cash and the income generated from capital goods). Because capital depreciates fully at the end of each period and because preferences are quasi-linear, without loss of generality, we can restrict attention to "static" contracts. ${ }^{9}$ Moreover, we assume that banks behave symmetrically in equilibrium. From this point on any reference to a bank should be understood to mean a representative pricetaking bank unless it is otherwise noted.

Measured in units of afternoon output, afternoon cash reserves are given by $(\beta / \mu) x$ and capital goods are given by $k$. Let $\left(k_{2}, y_{2}\right)$ denote the amount of capital goods and cash, respectively, used to finance $c_{2}$. Let $\left(z_{1}^{+}, z_{2}^{+}\right)$denote the purchasing power of cash carried into the next morning by the impatient and patient investors, respectively. Then, the bank faces the following afternoon budget constraint

$$
(\beta / \mu) x+r\left(k-k_{2}\right)-y_{2}-\beta z_{1}^{+}-\beta z_{2}^{+}=\pi c_{1}
$$

The evening budget constraint is given by

$$
R k_{2}+y_{2}=(1-\pi) c_{2}
$$

Given assumptions [A1] and [A2], it is straightforward to demonstrate that optimality will entail the following: (i) $k_{2}=k$ (capital goods are not used prematurely), (ii) $y_{2}=0$ (cash will never be used to finance evening consumption), and (iii) $z_{1}^{+}=0$ (impatient depositors spend all their cash in the afternoon). Thus, in what follows, we impose these restrictions beforehand to enhance the clarity of the exposition.

As an aside, note that we can think of banks here either as a depositor-cooperative, or as a monopoly bank interested in maximizing its own profit. In this latter case, we could assume that banks have linear preferences over morning output. As such, we could model banks as designing deposit contracts $\left(y, c_{1}, c_{2}\right)$ that maximize the expected welfare of depositors, charging depositors a lump-sum participation fee $f$ in the morning for services rendered. A monopoly bank would be able to charge a fee $f$ that extracted the entire investor

\footnotetext{
${ }^{7}$ Alternatively, workers can sell their labor for money in the morning and then deposit their cash receipts with their bank.

${ }^{8}$ In particular, the bank uses its liabilities (bank money) to purchase labor from investors, or new capital goods from firms that hire this labor.

${ }^{9}$ That is, we may assume without loss in generality that cash net of afternoon redemptions taken into the evening are fully paid out, along with any returns to capital. See also Berentsen, Camera and Waller (2007).
} 
surplus (their gains from entering into the banking arrangement net of the payoff associated with their next best alternative). Because utility is transferable here (i.e., preferences are quasilinear), the amount of surplus extracted by a monopoly bank would in no way affect the equilibrium allocation $\left(c_{1}, c_{2}\right)$. In what follows, we assume that markets are contestable (Baumol, 1982), so that the fee $f$ is, in equilibrium, bid down to the cost of banking (normalized to zero here). The point of mentioning this here is that in what follows, parameter changes that affect depositor welfare could equally well be interpreted as affecting bank profits to the extent that banks have some bargaining power.

Let $W(z)$ denote the welfare of a depositor who enters the morning with real money balances $z$. Competition will drive banks to create a depositor base sufficiently large to diversify away idiosyncratic liquidity risk. A competitive and fully diversified bank maximizes the representative depositor's welfare by solving the following problem,

$$
W(z) \equiv \max _{x, k, z_{2}^{+}} z-x-k+\pi u\left(c_{1}\right)+(1-\pi)\left[u\left(c_{2}\right)+\beta W\left(z_{2}^{+} /(1-\pi)\right)\right]
$$

subject to $z_{2}^{+} \geq 0, \pi c_{1}=(\beta / \mu) x-\beta z_{2}^{+},(1-\pi) c_{2}=R k$, and the incentive-compatibility condition

$$
u\left(c_{2}\right)+\beta z_{2}^{+} /(1-\pi) \geq u\left(c_{1}\right)
$$

Condition (40) ensures truthful revelation on the part of patient investors, i.e., they will prefer to wait until the evening to withdraw their deposits. ${ }^{10}$

Let $\beta \psi$ denote the Lagrange multiplier associated with the non-negativity constraint $z_{2}^{+} \geq 0$, and $\phi$ the Lagrange multiplier for the incentive constraint (40). Using $W^{\prime}(z)=1$, the conditions for optimality are given by

$$
\begin{aligned}
(1-\phi / \pi)(\beta / \mu) u^{\prime}\left(c_{1}\right) & =1 \\
{[1+\phi /(1-\pi)] R u^{\prime}\left(c_{2}\right) } & =1 \\
1+\phi\left[1 /(1-\pi)+u^{\prime}\left(c_{1}\right) / \pi\right]+\psi & =u^{\prime}\left(c_{1}\right)
\end{aligned}
$$

Let us conjecture (and then verify) that $\phi=0$. In this case, the banking allocation $\left(c_{1}, c_{2}\right)$ is determined by

$$
\begin{aligned}
(\beta / \mu) u^{\prime}\left(c_{1}\right) & =1 \\
R u^{\prime}\left(c_{2}\right) & =1
\end{aligned}
$$

From (44)-(45), $c_{2}>c_{1}$, since $R>\beta / \mu$. Thus, since $z_{2}^{+} \geq 0$, it follows that (40) is slack, which confirms our conjecture that $\phi=0$.

It is immediately evident from (44)-(45) that the banking equilibrium implements the first-best allocation at the Friedman rule. Moreover, because of the quasilinearity of preferences, the evening allocation is invariant to inflation. The afternoon allocation is strictly

\footnotetext{
${ }^{10} \mathrm{~A}$ patient depositor prefers to wait until the evening if the value of doing so is at least as large as the value of misrepresenting himself, i.e., declaring to be impatient and withdrawing in the afternoon. The bank contract needs to provide incentives for truthful revelation of type. Formally, this implies the incentive compatibility condition: $u\left(c_{2}\right)+\beta W\left(z_{2}^{+} /(1-\pi)\right) \geq u\left(c_{1}\right)+\beta W(0)$. Given that $W^{\prime}(z)=1, W(z)=W(0)+z$; thus, the incentive compatibility condition simplifies to $(40)$.
} 
decreasing in the rate of inflation, reflecting the usual inflation-tax effect on cash goods. For the preferences given in [A3], conditions (44)-(45) imply that the bank allocation is given by,

$$
\begin{aligned}
& c_{1}^{B}=(\beta / \mu)^{1 / \sigma} \leq c_{1}^{*} \\
& c_{1}^{B}=R^{1 / \sigma}=c_{2}^{*}
\end{aligned}
$$

Proposition 2 Assume [A1] and [A3]. The equilibrium allocation in the banking economy possesses the following properties: (i) $c_{1}^{B}(\mu)<c_{1}^{*}$ and is strictly decreasing in $\mu$, with $c_{1}^{B}(\beta)=c_{1}^{*}$; (ii) $c_{2}^{B}=c_{2}^{*}$ and is invariant to $\mu$.

Finally, it is of some interest to note that under a banking arrangement, it is never optimal for either banks or depositors to carry "excess" cash over time. Combining (44) with (43) implies

$$
\psi=\mu / \beta-1
$$

Thus, for inflation rates satisfying $\mu>\beta$, we have $z_{2}^{+}=0$. When $\mu=\beta$ we have $z_{2}^{+} \geq 0$, but we can set $z_{2}^{+}=0$ without loss of generality. This is in contrast with the securities market equilibrium where patient investors found it optimal to carry excess cash balances over time for inflation rates $\mu \leq \mu_{0}$.

\subsection{Comparing banks and markets}

In this section, we compare equilibrium allocations under a securities market (36)-(37) with a banking system (46)-(47). The first thing to note is that both institutions deliver the optimal level risk-sharing arrangement when monetary policy follows the Friedman rule. Away from the Friedman rule, the banking arrangement offers superior risk-sharing than the securities market and hence, higher ex ante welfare for depositors.

Proposition 3 Assume [A1] and [A2]. Investors' welfare in a competitive banking equilibrium is greater than in a competitive securities market equilibrium; that is, $W(z)>V(z)$, for all $z \geq 0$.

The differences in allocations depend on whether inflation is below or above the threshold $\mu_{0}$ we identified above. For impatient investors we have

$$
c_{1}^{B} / c_{1}^{D}=\left\{\begin{array}{lll}
\pi^{-1 / \sigma}[1-(1-\pi)(\beta / \mu)]^{1 / \sigma} & \text { if } \quad \mu<\mu_{0} \\
{\left[\pi+(1-\pi)(R \mu / \beta)^{1-\sigma}\right]^{-1 / \sigma}} & \text { if } \quad \mu \geq \mu_{0}
\end{array}\right.
$$

Given [A1] and [A2], it is easy to show that $c_{1}^{B}>c_{1}^{D}$ for all $\mu>\beta$. Also, from the expressions above, it is clear that the distance between $c_{1}^{B}$ and $c_{1}^{D}$ increases with inflation.

Since evening consumption is at its first-best level in the banking equilibrium, the allocation here dominates the market allocation for all inflation rates. In particular, $c_{2}^{B}=c_{2}^{*}<c_{2}^{D}$ for all $\mu>\beta$. Furthermore, given Proposition 1 the distance between $c_{2}^{B}$ and $c_{2}^{D}$ also increases with inflation. Thus, as inflation rises, the consumption of impatient and patient 
investors spreads out more rapidly in the market economy than with banking. Thus, even though welfare under both types of arrangements suffers with higher inflation rates, banking becomes relatively more valuable as inflation increases.

The allocation under banking can be viewed as constrained-efficient in the sense that the banking equilibrium replicates what a planner facing a rate of return of $\beta / \mu$ between morning and afternoon would implement. This is analogous to assuming the rate of return on the short-term technology in a standard Diamond-Dybvig setup may be less than one; in this case, banks would implement the first-best for any given rate of return on the short-term technology. The difference is that in our model the short-term rate of return is determined by government policy rather than technology.

Unlike the standard result in the banking literature, however, the market economy here implements the first-best when the rate of return on money is just right (i.e., at the Friedman rule), regardless of preferences. As we explained above, allowing investors to save money across periods is critical for this result. Away from the Friedman rule, the market and banking allocation differ. This is because inflation taxes the idle money balances that investors in the market economy would like to hold across periods, creating an inefficiency in addition to the low rate of return between morning and afternoon. In contrast, banks do not hold idle cash and are thus not subject to this wedge since they face no aggregate uncertainty with respect to their liquidity needs.

Although through a different mechanism, the market economy here shares a property often found in models where money and capital must compete to some extent as stores of value: a high rate of inflation induces an overaccumulation of capital (Tobin, 1965). Interestingly, for the reasons mentioned above, the banking system here insulates long-term capital returns completely from inflation.

\section{Banking and securities markets}

To this point, we have studied two monetary economies, one with a securities market and one with a banking system. Each of these alternative liquidity risk-sharing mechanisms deliver the same afternoon and evening consumption when monetary policy operates at the Friedman rule. When monetary policy operates away from the Friedman rule, Proposition 3 asserts that a banking system delivers superior risk-sharing for investors. Proposition 3 , however, was derived under the assumption that bank depositors have no access to a securities market after types are revealed. While this assumption is commonly employed in the literature beginning with Diamond and Dybvig (1983), it is not innocuous-see Jacklin (1987), Haubrich (1988), von Thadden (1997) and Diamond (1997).

As in Diamond (1997), we want to think about banks coexisting with securities markets. To this end, imagine the existence of a large (infinite) but countable number (zero measure) of investors who are exogenously precluded from participating in the banking sector. These "unbanked" investors are compelled to behave in the manner described in Section 3. That is, they work to accumulate money and capital, that they then expect to trade in an ensuing securities market. Their trading behavior implies the existence of a securities market in 
which the price of capital goods measured in units of afternoon output is given by the noarbitrage-condition (26), i.e., $\rho=\beta / \mu$. We want to think about these unbanked investors as operating contemporaneously with another set of investors that do have access to banking services. From the perspective of any (measure zero) individual, the price $\rho=\beta / \mu$ is viewed parametrically. Thus, our approach here differs from Diamond (1997) who derives $\rho$ as an equilibrium object determined in a closed system given a parametric degree of limited participation.

Now, consider an investor who turns out to be patient in the afternoon. Since the incentive-compatibility condition (40) holds, he clearly prefers to withdraw his funds at the later date-assuming his only option is to spend what he withdraws on afternoon consumption. However, if the depositor has access to the securities market described above, then instead of spending the cash he withdraws on afternoon goods, he could instead use it to purchase capital goods at price $\rho=\beta / \mu$. The question is how the opportunity for securities market trading impinge on the ability of banks to offer liquidity insurance.

In what follows, we assume that each patient investor gains access to the securities market with probability $0 \leq \eta \leq 1$ (so that a measure $\eta$ of patient investors potentially have access to the securities market in each period). The effect here is to limit market participation along the lines of Diamond (1997). When $\eta=0$, patient investors are shut out of the securities market completely, so that the analysis collapses to the scenario studied earlier. As $\eta \rightarrow 1$, patient depositors gain access the securities market with greater ease. Again, we assume no aggregate uncertainty so that $\eta$ also represents the measure of patient depositors that gain access to the securities market. As in Diamond (1997) impatient investors always have access to the securities market. ${ }^{11}$ Finally, we assume that depositors realize their "liquidity shock" after making their morning deposit but prior to visiting the bank in the afternoon. ${ }^{12}$

To begin our analysis, we establish that under the optimal bank contract of the previous section, patient investors with market access prefer to withdraw their cash early and use it to buy securities. Consider the following property of the bank allocation.

Lemma 3 Assume [A1] and [A2]. In a competitive banking equilibrium $(\mu / \beta) c_{1}>c_{2} / R$.

A patient depositor with market access can withdraw $c_{1}$ units of money in the afternoon, exchange it for capital at price $\rho=\beta / \mu$ and earn a return $R$ in the evening. The resulting evening consumption is equal to $R(\mu / \beta) c_{1}$, which by Lemma 3 is larger than $c_{2}$. Therefore, patient depositors with market access will withdraw their funds in the afternoon rather than wait until the evening. The deposit contract needs to be modified to take this behavior into account.

The bank anticipates that, in addition to impatient depositors, there will be a measure $\eta$ of patient depositors wishing to withdraw funds early. It sets aside $m_{t}^{a}$ dollars in reserve in the morning or, measured in units of afternoon consumption, $c_{1}=\left(m_{t}^{a} / p_{t}^{a}\right) /[(\pi+(1-\pi) \eta)]$.

\footnotetext{
${ }^{11}$ This assumption is immaterial in this section, as impatient depositors never have an incentive to access the market, but will come into play when we analyze bank runs.

${ }^{12}$ We have also studied the case for which the liquidity shock is realized after depositors make their withdrawal decision. Our essential results remain valid either way.
} 
Let $\tilde{k}$ denote number of securities purchased by a patient depositor with market access. Since the nominal value of purchased capital cannot exceed the cash withdrawn from the bank, we have $q_{t} \tilde{k} \leq m_{t}^{a} /[(\pi+(1-\pi) \eta)]$ or, in real terms, $\rho \tilde{k} \leq c_{1}$. Any unspent cash is carried into the next morning; hence, $\beta \tilde{z}_{2}^{+}=c_{1}-\rho \tilde{k} \geq 0$. The capital goods purchased in the securities market generate $\tilde{c}_{2}=R \tilde{k}$ consumption goods in the evening. Since $\rho=\beta / \mu$, we can combine these latter two expressions to write the budget constraint of the patient agents with market access as follows:

$$
\mu \tilde{z}_{2}^{+}=(\mu / \beta) c_{1}-\tilde{c}_{2} / R \geq 0
$$

As before, the bank faces an afternoon budget constraint and an evening budget constraint. The evening budget constraint is $(1-\pi)(1-\eta) c_{2}=R k$. The afternoon budget constraint is derived as follows. At the beginning of the afternoon, the bank holds $m_{t}^{a}$ units of money and each impatient investor and each patient investor with access receives $m_{t}^{a} /(\pi+(1-\pi) \eta)$ dollars. Hence, in real terms the budget constraint satisfies $(\beta / \mu) x=[\pi+(1-\pi) \eta] c_{1}$.

Let $W(z)$ denote the value of beginning the morning with real money balances $z$ and let $(1-\pi) \eta \tilde{\zeta}$ denote the Lagrange multiplier associated with the inequality constraint (49). Then, the choice problem facing a bank on behalf of an investor who enters the morning with real money balances $z$, satisfies

$$
W(z) \equiv \max _{x, k, \tilde{c}_{2}} z-x-k+\pi u\left(c_{1}\right)+(1-\pi) \eta\left[u\left(\tilde{c}_{2}\right)+\beta V\left(\tilde{z}_{2}^{+}\right)\right]+(1-\pi)(1-\eta) u\left(c_{2}\right)
$$

subject to (49), the bank's budget constraints $(\beta / \mu) x=[\pi+(1-\pi) \eta] c_{1}$ and $(1-\pi)(1-\eta) c_{2}=$ $R k$, and the incentive-compatibility conditions $\tilde{c}_{2} \geq c_{2} \geq c_{1}$, which will be verified to hold in due course. The first-order conditions satisfy

$$
\begin{aligned}
\pi(\beta / \mu) u^{\prime}\left(c_{1}\right)+(1-\pi) \eta R u^{\prime}\left(\tilde{c}_{2}\right) & =\pi+(1-\pi) \eta \\
R u^{\prime}\left(c_{2}\right) & =1 \\
R u^{\prime}\left(\tilde{c}_{2}\right) & =\beta / \mu+\tilde{\zeta}
\end{aligned}
$$

Proposition 4 Assume [A1]. When $\eta=1$ (frictionless access to the securities market) the banking system is constrained to offer the risk-sharing allocation available in securities markets. When $\eta=0$ (no access to the securities market), the banking allocation is implemented.

Proposition 4 is related to Diamond (1997) who, like us, asks how the ex post availability of markets disciplines the amount of risk-sharing that can be made available through banks. ${ }^{13}$

\footnotetext{
${ }^{13}$ Diamond (1997) also considers the restrictions placed by the possibility of an ex ante deviation, which was also considered by Jacklin (1987). The deviation in this case has an investor bypass the bank and directly acquire only capital in the morning. If he turns out to be patient he enjoys the high return to his large capital investment. If he turns out to be impatient he uses the securities market to sell it. As it turns out, this deviation places no additional restrictions in our model.
} 
Proposition 5 Assume [A1] and $\eta \in[0,1]$. The first-best allocation is implementable only at the Friedman rule; i.e., as $\mu \searrow \beta$. Moreover, assuming [A2], first-best implementation requires that patient investors with access carry strictly positive amounts of money across periods.

In the proof of Proposition 5, we show that the savings constraint is not binding at the Friedman rule implying that $\tilde{\zeta}=0$. Then, from (50)-(52), it immediately follows that $c_{1}=c_{1}^{*}$ and $c_{2}=\tilde{c}_{2}=c_{2}^{*}$. Given our previous analysis, it is not surprising that the first-best allocation is attainable at the Friedman rule. Nevertheless, the result is important because it shows again that it is critical that investors have an opportunity to save across periods in order to implement efficient liquidity insurance.

We now study the properties of the model for $\eta \in(0,1)$, away from the Friedman rule. As suggested by conditions (50)-(52), the allocation may depend on whether patient depositors with market access carry some of the cash to the following morning. We identify a critical value for inflation, $\bar{\mu}$, such that patient depositors with market access do not save any cash for all $\mu \geq \bar{\mu}$.

Proposition 6 Assume [A1], [A3] and $\eta \in(0,1)$. The equilibrium allocation when banks coexist with securities markets has the following properties: (i) $c_{1}<c_{1}^{*}<c_{2}^{*}=c_{2}<\tilde{c}_{2}$; (ii) $d c_{1} / d \mu<0, d c_{2} / d \mu=0, d \tilde{c}_{2} / d \mu>0$; (iii) $d c_{1} / d \eta<0, d c_{2} / d \eta=0 ; d \tilde{c}_{2} / d \eta=0$ if $\mu<\bar{\mu}$ and $d \tilde{c}_{2} / d \eta<0$ if $\mu \geq \bar{\mu}$.

Result (i) characterizes the allocation when banks and securities markets coexist, away from the Friedman rule. In this case, impatient depositors consume less than the firstbest, while patient depositors with market access consume more than the first-best. Hence, the presence of markets impinges on the ability of banks to provide liquidity insurance. Notably, patient agents without market access consume the first-best allocation, regardless of the inflation rate and the degree of market access. The reason for this last result is that the bank holds capital only to provide for the consumption of patient depositors without market access. The consumption of all other depositors is supported by cash holdings.

Result (ii) asserts that the effects of higher inflation on the allocation are a mix of what is predicted to happen when securities markets and banking arrangements operate in isolation to each other. First, inflation reduces the return to those that need to withdraw cash for consumption purposes, i.e., impatient depositors. Second, the bank protects the purchasing power of deposits left in the bank, which do not require to be supported by cash. Third, for those patient depositors with market access, who withdraw cash to finance the purchase of securities, inflation actually improves their allocation as it makes capital cheaper.

Result (iii) asserts that technological developments that alter the ease of securities market access tend to have a detrimental role on the ability of banks to provide liquidity insurance. In our set up, increasing the access parameter $\eta$ has no effect on the return to long-term deposits. ${ }^{14}$ Instead, the effect is to lower the return on short deposits. The

\footnotetext{
${ }^{14}$ This is in contrast to Diamond (1997) where a change in the market access parameter affects the equilibrium price $\rho$.
} 
effects on the allocation for patient depositors with market access depend on inflation: for low enough inflation rates, their consumption remains constant as market access increases (the impact is on cash savings); for high enough inflation rates, their consumption decreases in tandem with that of impatient consumers as market access increases. The consumption of those depositors withdrawing in the afternoon suffers with increased market access, as the bank's cash needs to be divided among more depositors.

\subsection{Related literature}

It is some interest to compare our results relative to Farhi, Golosov and Tsyvinski (2009) and a closely related paper by Allen and Gale (2004). These authors highlight the interaction of two key frictions: private information over preference types and unobservable side trades. Our paper adds a dynamic dimension and an additional friction-a lack of commitment over debt repayment-that generates a demand for money.

Farhi, et. al. (2009) demonstrate the usual under-provision of liquidity that occurs when ex post trading cannot be discouraged. They then demonstrate how an intervention in the form of broad-based minimum reserve requirement can be selected such that banking equilibrium with side trades implements the efficient risk-sharing allocation. The intervention works through a general equilibrium effect. In particular, a legislated increase in bank reserves has the effect of lowering the equilibrium interest rate on the long-maturity instrument. This, in turn, has the effect of discouraging patient depositors from cashing out early for the purpose of arbitrage (i.e., by re-investing the proceeds in the long-maturity instrument).

The same type of restriction will not work in our environment as we have (by construction) abstracted from the interest rate effect of aggregate liquidity provision. ${ }^{15}$ In our model, arbitrage relates the rate of return on the long-maturity instrument to the inflation rate. Nevertheless, there is a sense in which our preferred intervention-the Friedman ruleshare the flavor of the Farhi, et. al. (2009) result. In particular, by running a deflation, the monetary authority increases the rate of return on the short-instrument (cash) and lowers the rate of return on the long-instrument (securities). This is exactly the type of relative price distortion that is necessary to correct the externality generated by the market frictions in this environment.

\section{$5 \quad$ Bank panics and securities markets}

Consistent with the literature we have cited repeatedly above, the analysis here supports the idea that banks are generally superior to markets as mechanisms for delivering liquidity insurance. However, to the best of our knowledge no one has asked how the availability of markets interacts with bank sector fragility. The main purpose of Diamond and Dybvig (1983), of course, was to formalize the notion of bank sector "fragility" and the rationale

\footnotetext{
${ }^{15}$ Recall that we assumed a large measure of unbanked investors that determined the equilibrium securities price $\rho=\beta / \mu$.
} 
for deposit insurance. How are the results we derived above sensitive to the existence of bank panic equilibria?

In what follows, we assume a form of contractual incompleteness that gives rise to the existence of a bank panic-a situation in which all patient depositors misrepresent themselves as being impatient. In particular, we assume that the bank contract described above does not anticipate the possibility of a panic. Moreover, we assume that banks cannot commit to suspending redemptions after cash reserves are depleted. Instead, we simply assume that if the contractually stipulated early redemption promise cannot be met for every depositor requesting early redemption, then the bank becomes bankrupt and is forced to disperse its assets in some prescribed manner. Below, we consider an number of ways in which bankrupcty is resolved.

Before commencing with the analysis, note that from the budget constraints of the bank problem, we know how the bank asset portfolio is related to depositors' allocations when there is no panic: $(\beta / \mu) x=[\pi+(1-\pi) \eta] c_{1}$ and $R k=(1-\pi)(1-\eta) c_{2}$. Recall that, from (49), $\tilde{c}_{2}=R(\mu / \beta) c_{1}$ if patient depositors with market access do not save any cash in the following period, and $R u^{\prime}\left(\tilde{c}_{2}\right)=\beta / \mu$, otherwise. The following result will be useful for the analysis below.

Lemma 4 Assume [A1], [A2] and $\eta \in[0,1)$. Then $c_{2}<R(\mu / \beta) c_{1}$ and $(\beta / \mu)(x+k)<c_{1}$.

The resolution of a bank panic depends on whether the bank itself has access to the financial market or not. Even in that case it may not be optimal to access the market an convert capital into cash. We consider each case in turn.

\subsection{Bankruptcy}

\subsubsection{Asset liquidation}

Suppose that banks are forced to liquidate their assets in the event of bankruptcy. Implicit in our assumption that $\rho=\beta / \mu$ is that the bank sector is small relative to the whole economy. ${ }^{16}$ While this assumption rules out the effect of "firesales" on asset prices, it allows us to focus on other forces that determine depositor welfare. In any case, given $\rho=\beta / \mu$, the bank sells $k$ units of investment for $\rho k$ units of cash (measured in units of afternoon consumption). At the end of the liquidation process, the bank has real money balances totalling $(\beta / \mu)(x+k)$, which it disperses on a pro rata basis to depositors (all of whom are asking for cash in the afternoon). By Lemma $4,(\beta / \mu)(x+k)<c_{1}$ (if this condition were not to hold, then the bank would be in a position to fulfil its early redemption promises, so that a panic could not be an equilibrium).

What do depositors do with the cash they receive? The answer depends on what trading opportunities depositors have. Impatient depositors simply spend their cash in the afternoon goods market, receiving $c_{1}^{l}=(\beta / \mu)(x+k)$, where the superscript $l$ denotes "liquidation."

\footnotetext{
${ }^{16}$ This assumption would apply, for example, for a small open country with few banks and where capital is traded innternationally.
} 
The measure $1-\eta$ of patient depositors that do not access the securities market are compelled to spend their cash for afternoon goods as well, which they store into the evening for a payoff $c_{2}^{l}=(\beta / \mu)(x+k)<c_{2}$. The measure $\eta$ of patient depositors who gain access to the securities market can acquire a maximum of $x+k$ units of capital goods; however, they may want to carry over some cash to the following period. Thus, $\tilde{c}_{2}^{l}=R\left(x+k-\beta \tilde{z}_{2}^{l}\right)$. Note that $\tilde{z}_{2}^{l}=0$ as long as $R u^{\prime}(R(x+k)) \geq 1$ and $\tilde{z}_{2}^{l}>0$ otherwise. Note that when $\mu \geq \bar{\mu}$ (so that these investors do not save cash in the no-run case), by (49), $R \mu / \beta c_{1}=\tilde{c}_{2}$. Using Lemma 4 and the bank's budget constraints one can show that $R(x+k)<\tilde{c}_{2}$. In other words, patient depositors with market access do not save any cash in the event of a run either and so, $\tilde{c}_{2}^{l}=R(x+k)<\tilde{c}_{2}$.

\subsubsection{Clearinghouse certificates}

Cash liquidations are not the only way to handle an unexpected mass redemption event. An alternative protocol is to disperse assets on a pro rata basis through equity shares, leaving depositors with the option of whether to hold or liquidate claims to bank assets. In effect, this protocol converts debt to equity, an operation sometimes used in the business sector when firms are under financial distress. In the context of banking, the practice was used extensively during the U.S. National Banking Era (1863-1913); see Gorton (1988). In particular, mass redemption events were often dealt with by having banks coalesce into a consolidated entity, suspending cash redemptions, and issuing clearinghouse certificates representing claims against the assets of the consolidated entity. These claims would circulate in secondary markets and once the crisis passed, operations returned to normal.

In what follows, we assume that the bank disperses its cash holdings on a pro rata basis, so that the certificates it issues constitute claims to its investments $k$. How does this mechanism differ from cash liquidation in our model? As before, we need to ask what depositors do with their certificates which, in turn, depends on what trading opportunities they have available. Impatient depositors need cash, so they will want to dispose of their certificates in the securities market. In this case, impatient depositors receive $(\beta / \mu)(x+k)$, as before. Likewise, the measure $\eta$ of patient depositors who gain access to the securities market can acquire $x+k$ units of capital goods, which return up to $R(x+k)$ units of evening consumption, which is the same as before. The group treated differently are the patient depositors without market access, who in this case obtain a higher consumption allocation: $c_{2}^{\prime}=(\beta / \mu) x+R k>c_{2}^{l}=(\beta / \mu)(x+k)$. Using the bank's budget constraints and the fact that $c_{1}<c_{2}$, it is easy to show that $c_{2}^{\prime}=(\beta / \mu) x+R k<c_{2}$, i.e., even in this case, patient depositors without market access receive less than they were promised by the bank contract.

It is interesting to note that our model supports the idea of satisfying depositor demands through the use of cash and certificates over the use of cash alone. The reason for this hinges on the pattern of market access. When the bank liquidates, it provides cash to depositors that would have preferred to keep their investment. If these depositors have difficultly in rebalancing their portfolio (in our model because market access is costly or imperfect), then they are made worse off by being forced to hold a low-yielding asset. If these depositors were instead handed certificates representing claims to investment, the bank is in effect moving their portfolio in the direction they want. That is, why liquidate securities on behalf of 
depositors who wish to stay invested? In this case, they spend their cash on afternoon goods and hold their certificates until they mature in the evening. The resulting allocation dominates what they would have received if they had instead been given cash only.

\subsection{A trade-off between insurance and stability}

Banks offer superior liquidity insurance relative to markets. But if banks are subject to panics, then the benefit of this added insurance must be weighed against the costs of disruptions in the payments system. It is interesting to note that conditional on a bank panic, the cost of the subsequent disruption is smaller for economies in which depositors have easier access to securities markets. Hence, there is a sense in which the availability of securities markets helps stabilize the financial system.

On the other hand, our analysis suggests that such stability will come at a cost. In particular, as access to securities markets becomes progressively less costly over time, the ability of banks to provide superior liquidity insurance arrangement will diminish accordingly. The quantitative impact of these developments is predicted here to depend largely on the inflation rate regime. For high inflation rate regimes, the economic benefits of liquidity insurance through the banking sector is higher. But for low inflation rate regimes, the welfare gains of banks over markets diminish. We conclude that a policy of keeping keeping inflation low and stable as access to financial markets improves over times seems like a good way to promote financial stability along with ensuring access to liquidity insurance.

\section{Lender of last resort}

The Diamond and Dybvig (1983) framework is a static, non-monetary model. Accordingly, the type of crisis-prevention intervention they studied-deposit insurance-was non-monetary in nature. In reality, most debt obligations constitute promises to deliver money. And in a panic, banks have trouble meeting their short-run nominal obligations. This leads to the question of whether an emergency money-lending facility-a lender-of-last-resort-might be designed in a manner to eliminate bank panics.

The lender-of-last-resort function associated with central banking has a long history. Rolnick and Weber (1998), for example, describe how the Suffolk Bank (a private bank) acted as a clearinghouse and lender-of-last-resort for the Suffolk Banking System in 19th century New England. Evidently, the Suffolk bank extended loans of specie to its member banks during the crisis of 1837, an action the authors credit with rendering the the ensuing recession in the New England area much less severe than in other parts of the country.

Of course, the Suffolk Bank had to rely on reserves of cash in the form of specie. The inelastic supply of specie in commodity money systems is likely what motivated Bagehot (1873) to suggest that central banks lend freely but at "high rates" against good collateral to help stem a bank panic. In particular, Bagehot (1873, chapter 7 ) wrote his first principle as:

First. That these loans should only be made at a very high rate of interest. 
This will operate as a heavy fine on unreasonable timidity, and will prevent the greatest number of applications by persons who did not require it. The rate should be raised early in the panic, so that the fine may be paid early; that no one may borrow out of idle precaution without paying well for it; that the Banking reserve may be protected as far as possible. (italics our own).

That is, the so-called penalty rate of interest was designed to help protect central bank reserves against depletion. Note that such a constraint is entirely absent if cash takes the form of fiat money instead of specie (or any other commodity). One is led to speculate whether lending freely against good collateral at a low rate of interest might not be optimal in a fiat money based system. Indeed, Antinolfi, Hybens and Keister (2001) show that in their model, zero-interest emergency loans are exactly the correct policy for a fiat-based central bank concerned with stemming a liquidity crisis. ${ }^{17}$

We think that a monetary economy is essential for evaluating the efficacy of a central bank lender-of-last-resort policy over other types of interventions designed to stabilize financial markets. The reason for this is based on the simple fact that modern day central banks can costlessly manipulate the supply of base money-which is closely related to the object of redemption in bank deposit contracts. To be sure, the ability to costlessly create money "out of thin air" is often portrayed as a defect, especially for those who fear that governments are too easily seduced by the prospect of inflation finance. But precisely because creating money in this manner is costless, the threat of injecting money into the banking system if it is needed can be made perfectly credible. This is in contrast to fiscal interventions, which must invariably resort to tax finance (either contemporaneous or postponed). While it is possible that a government treasury may raise the money needed for emergency lending, why not simply have the central bank create the needed money at a stroke of a pen?

What is interesting here is that the ability of a central bank lending facility to eliminate bank panics is enhanced greatly if bank deposit contracts are stipulated in nominal termsas they are in reality. A private bank's ability to make good on a nominal promise can be made perfectly credible if it has access to a central bank lending facility. So, let us reconsider our model above and assume that banks and depositors contract in nominal terms, understanding that banks have access to a central bank lending facility that will help banks honor early redemption requests in any state of the world. Because the central bank's promise is stated in nominal terms, it is clearly credible. And because banks now do not need to liquidate capital unnecessarily, patient investors know that their deposits will safe and available for evening withdrawal; hence, a self-fulfilling bank panic cannot exist in equilibrium. In this way, depositors may reap the benefits of banking without fearing the losses that are incurred in a banking panic. ${ }^{18}$ In our model, a central bank lending facility would have the most merit in economies where securities markets are relatively less

\footnotetext{
${ }^{17}$ Champ, Smith and Williamson (1996) suggest that panics can also be avoided by permitting banks themselves to issue currency.

${ }^{18}$ Of course, offsetting this benefit is the prospect of moral hazard induced by the lending facility. While our model abstracts from moral hazard, it seems clear that if it was operative, then the obvious trade-off would present itself.
} 
developed (low $\eta$ ) and the inflation rate is high (say, because money finance constitutes an important source of revenue for the government).

The notion of nominal debt being conducive to financial stability has been recently explored by Allen, Carletti and Gale (2014). Their model, like ours, relies on some notion of contractual incompleteness. A similar idea underpins the notion of nominal GDP targeting as optimal policy; see, for example, Koenig (2013).

\section{Conclusion}

Much of what we have learned from the canonical Diamond and Dybvig (1983) and Diamond (1997) models of banking and financial markets appears to remain intact when we extend that framework to a dynamic setting where fiat money plays an essential role. In particular, banks and securities markets remain competing mechanisms for liquidity insurance and bank deposit contracts remain constrained by degree of financial market development. Moreover, the fragility of banking structures that rely extensively on simple demand deposit liabilities as a form of financing remains a possibility.

Embedding the canonical banking framework in a dynamic monetary model yields the following additional insights. First, in non-monetary versions of the framework, the rate of return on the short asset is determined by technology. In a monetary model, inflation policy affects the rate of return on the short asset. Of course, the same would be true in a non-monetary model that considered a distortionary tax or subsidy on some asset classes. In a monetary version of the model, this type of tax wedge emerges naturally and becomes an integral part of the analysis. In particular, we have demonstrated how a competitive securities market can produce efficient liquidity insurance if inflation policy follows the Friedman rule. Notably, allowing for money savings across periods, a natural property of monetary models, is essential for this result to hold. In addition, we demonstrated how the welfare benefit associated with banking vis-à-vis markets is larger in economies with higher target inflation rates.

We have also shown how the degree of securities market liquidity introduces an interesting trade-off between banks and markets as liquidity insurance mechanisms. Conditional on a bank panic, a more liquid a securities market results in less disruption. However, an ex ante more liquid securities market implies less efficient liquidity insurance and, moreover, this is especially true in high-inflation regimes. Finally, consistent with other recent research, the model provides a possible rationale for nominal debt combined with a central bank lender-of-last-resort facility to promote efficient liquidity insurance and a panic-free banking system. 


\section{References}

1. Allen, Franklin and Douglas Gale (2004). Financial Intermediaries and Markets. Econometrica 72, 1023-1061.

2. Allen, Franklin and Douglas Gale (2007). Understanding Financial Crises. Oxford University Press, New York.

3. Allen, Franklin, Carletti, Elena and Douglas Gale (2014). "Money, Financial Stability and Efficiency," Journal of Economic Theory, 149: 100-127.

4. Andolfatto, David (2013). "Incentive-Feasible Deflation," Journal of Monetary Economics, 60(4): 383-390.

5. Antinolfi, Gaetano, Huybens, Elizabeth and Todd Keister (2001). "Monetary Stability and Liquidity Crises: The Role of the Lender of Last Resort," Journal of Economic Theory, 99: 187-219.

6. Bagehot, Walter (1873). Lombard Street: A Description of the Money Market, London: Henry S. King and Co.

7. Baumol, William J. (1982). "Constable Markets: An Uprising in the Theory of Industry Structure," The American Economic Review, 72(1): 1-15.

8. Berentsen, Aleksander, Gabriele Camera and Christopher Waller (2007). "Money, Credit and Banking," Journal of Economic Theory 135, 171-195.

9. Champ, Bruce, Bruce D. Smith and Stephen D. Williamson (1996), "Currency Elasticity and Banking Panics: Theory and Evidence," Canadian Journal of Economics, $29(4): 828-864$.

10. Cooper, Russell and Ross, T.W. (1998). "Bank runs: liquidity costs and investment distortions", Journal of Monetary Economics 41, 27-38.

11. Diamond, Douglas and Philip Dybvig (1983). "Bank Runs, Deposit Insurance, and Liquidity", Journal of Political Economy 91(3): 401-419.

12. Diamond, Douglas (1997). "Liquidity, Banks, and Markets," Journal of Political Economy, 105(5): 928-956.

13. Farhi, Emmanuel, Golosov, Mikhail and Aleh Tsyvinski (2009). "A Theory of Liquidity and Regulation of Financial Intermediation," Review of Economic Studies, 76: 973-992.

14. Gale, Doug (1978). "The Core of a Monetary Economy without Trust," Journal of Economic Theory, 19(2): 456-491.

15. Gorton, Gary (1988). "Banking Panics and Business Cycles," Oxford Economic Papers, 40: 751-781. 
16. Haubrich, Joseph G. (1988). "Optimal Financial Structure in Exchange Economies," International Economic Review, Vol. 29(2): 217-35.

17. Jacklin, Charles J. (1987). "Demand Deposits, Trading Restrictions, and Risk Sharing," in E. Prescott and N. Wallace (eds), Contractual Arrangements for Intertemporal Trade, Minneapolis, MN: University of Minnesota Press, 26â€"47.

18. Koenig, Evan (2013). "Like a Good Neighbor: Monetary Policy, Financial Stability, and the Distribution of Risk," International Journal of Central Banking, 9(2): 57-82.

19. Lagos, Ricardo and Randall Wright (2005). "A Unified Framework for Monetary Theory and Policy Analysis" Journal of Political Economy 113(3): 463-484.

20. Loewy, B. Michael (1991). "The Macroeconomic Effects of Bank Runs: An Equilibrium Analysis," Journal of Financial Intermediation 1: 242-256.

21. Rolnick, Arthur and Warren Weber (1998). "The Suffolk Bank and the Panic of 1837: How a Private Bank Acted as a Lender of Last Resort," Federal Reserve Bank of Minneapolis, Working Paper 592.

22. Smith, D. Bruce (2002). "Monetary Policy, Banking Crises, and the Friedman Rule," Macroeconomics of Incomplete Markets: AEA Papers and Proceedings, 92(2): 128134 .

23. Tobin, James (1965). "Money and Economic Growth," Econometrica, 33(4): 671-684.

24. von Thadden, Ernst-Ludwig (1997). "The Term Structure of Investment and the Banks' Insurance Function," European Economic Review, 41(3): 1355-1374. 


\section{A Proofs}

Proof of Lemma 1. In any equilibrium with positive money and capital holdings, $r \leq \rho \leq R$. Suppose first that $\rho>r$. Then, an impatient investor is strictly better off by selling all his capital, i.e., $k_{1}=k$. Optimality implies $c_{1}=(\beta / \mu) x+\rho k_{1}-\beta z_{1}^{+}>0$; thus, (14) is satisfied with strict inequality. Next, suppose that $\rho=r$. In this case, the impatient investor receives the same consumption allocation whether he sells or consumes the return to capital goods. However, selling capital goods relaxes the constraint (14); thus, $k_{1}$ increases until either (14) is satisfied with equality or $k_{1}=k$, in which case $c_{1}>0$. This again implies (14) is satisfied with strict inequality.

Constraints (16) and (18) imply (17).

Proof of Lemma 2. Using the results derived in the main body of the text, we can write the first-order conditions (20)-(24) as follows:

$$
\begin{aligned}
u^{\prime}\left(c_{1}\right) & =1+\zeta_{1} \\
R(\mu / \beta) u^{\prime}\left(c_{2}\right) & =1+\zeta_{2} \\
\pi u^{\prime}\left(c_{1}\right)+(1-\pi) R(\mu / \beta) u^{\prime}\left(c_{2}\right) & =\mu / \beta .
\end{aligned}
$$

Furthermore, since $\beta z_{1}^{+}=(\beta / \mu)(x+k)-c_{1}$ and $\beta z_{2}^{+}=(\beta / \mu)[x+\pi k /(1-\pi)]$ the Kuhn-Tucker conditions are

$$
\begin{gathered}
\zeta_{1}\left[(\beta / \mu)(x+k)-c_{1}\right]=0 \\
\zeta_{2}(\beta / \mu)\left(x-\frac{\pi}{1-\pi} k\right)=0
\end{gathered}
$$

There are four possible cases for the values of the multipliers $\zeta_{1}$ and $\zeta_{2}$.

1) Assume $\zeta_{1}=\zeta_{2}=0$ : both types save money across period. Then, from (53)(55), we get $1=\mu / \beta$. This case is only possible under the Friedman rule.

2) Assume $\zeta_{1}>0$ and $\zeta_{2}=0$ : patient investor saves money across periods. Then, from (53)-(55), we obtain

$$
u^{\prime}\left(c_{1}\right)=\frac{\mu / \beta-(1-\pi)}{\pi} \text { and } R(\mu / \beta) u^{\prime}\left(c_{2}\right)=1,
$$

and from (28), (56), and (57) we obtain

$$
c_{1}=(\beta / \mu)(x+k), c_{2}=R k /(1-\pi) \text { and }(1-\pi) x \geq \pi k .
$$

Existence of case 2 requires that

$$
u^{\prime}\left(c_{1}\right) \geq 1 \text { and }(1-\pi) x \geq \pi k
$$


It is easy to show that $u^{\prime}\left(c_{1}\right)=\frac{\mu / \beta-(1-\pi)}{\pi}>1$, unless $\mu=\beta$. Rewrite $(1-\pi) x \geq \pi k$ to get $(1-\pi)(x+k) \geq k$. Use $(59)$ to get

$$
c_{1} R(\mu / \beta) \geq c_{2}
$$

Use (58) to get

$$
u^{\prime}\left(c_{1}\right) c_{1} \geq \frac{\mu / \beta-(1-\pi)}{\pi} u^{\prime}\left(c_{2}\right) c_{2}
$$

This case requires $u^{\prime}(c) c$ to be decreasing as we assume with assumption [A2].

3) Assume $\zeta_{1}=0$ and $\zeta_{2}>0$ : impatient investor saves money across periods. Then, from (53)-(55), we obtain

$$
u^{\prime}\left(c_{1}\right)=1 \text { and } R(\mu / \beta) u^{\prime}\left(c_{2}\right)=\frac{\mu / \beta-\pi}{(1-\pi)}
$$

and from (28), (56), and (57) we obtain

$$
c_{1} \leq(\beta / \mu)(x+k), c_{2}=R k /(1-\pi) \text { and }(1-\pi) x=\pi k .
$$

Existence requires $R(\mu / \beta) u^{\prime}\left(c_{2}\right) \geq 1$ and $c_{1} \leq(\beta / \mu) x / \pi$. It is easy to show that $R(\mu / \beta) u^{\prime}\left(c_{2}\right)=R(\mu / \beta) \frac{1-(\beta / \mu) \pi}{(1-\pi) R}>1$, unless $\mu=\beta$. Rewrite $c_{1} \leq(\beta / \mu)(x+k)$ to get $c_{1} \leq(\beta / \mu) k /(1-\pi)$. Rewrite again to get

$$
c_{1} R(\mu / \beta) \leq c_{2}
$$

or

$$
u^{\prime}\left(c_{1}\right) c_{1} \frac{\mu / \beta-\pi}{1-\pi} \leq u^{\prime}\left(c_{2}\right) c_{2}
$$

This case requires $u^{\prime}(c) c$ to be increasing which our assumption [A2] precludes.

4) Assume $\zeta_{1}>0$ and $\zeta_{2}>0$ : no savings across periods.

Then, from (53)-(55), we obtain

$$
\pi u^{\prime}\left(c_{1}\right)+(1-\pi) R(\mu / \beta) u^{\prime}\left(c_{2}\right)=\mu / \beta,
$$

and from (28), (56), and (57) we obtain

$$
c_{1}=(\beta / \mu)(x+k), c_{2}=R k /(1-\pi) \text { and }(1-\pi) x=\pi k .
$$

Note that

$$
c_{2} / c_{1}=R(\mu / \beta) .
$$

Existence of this case requires that $u^{\prime}\left(c_{1}\right) \geq 1$ and $R(\mu / \beta) u^{\prime}\left(c_{2}\right) \geq 1$.

Proof of Proposition 1. Follows from (36) and (37). 
Proof of Proposition 2. Follows from (46) and (47).

Proof of Proposition 3. First, note that $V(z)=V(0)+z$ and $W(z)=W(0)+z$, so that $V(z)-W(z)=V(0)-W(0)$ for all $z \geq 0$. Second, note that a bank maximizes the ex ante welfare of an investor and can always implement the securities equilibrium allocation as feasibility is the only relevant constraint in the banking problem. Furthermore, given (58) (for the case when patient investors save cash) and (64) (for the case when patient investors do not save cash), $c_{1}<c_{2}$ in a securities equilibrium; hence, $\left(c_{1}, c_{2}\right)$ is an incentive compatible allocation for the bank.

We will now show that when $\mu>\beta$ the bank, despite being able to implement the securities equilibrium as shown above, chooses a different allocation. Thus, it must be that the bank allocation provides higher ex-ante utility for the investor, i.e., $W(z)>V(z)$. Suppose the securities equilibrium and the bank choose the same allocation. Then, both choose $c_{2}=c_{2}^{*}$ and so $k=k^{*}$. By $(25), \mu>\beta$ and $c_{2}=c_{2}^{*}$ imply $\zeta_{2}>0$ and so $z_{2}^{+}=0$. Then (32) applies in a securities equilibrium and so, $(\mu / \beta) c_{1}=c_{2}^{*} / R$, which contradicts Lemma 3. Thus, bank and markets implement different allocations.

Proof of Lemma 3. Given $c_{1}<c_{2}$, assumption [A2] implies $u^{\prime}\left(c_{1}\right) c_{1}>u^{\prime}\left(c_{2}\right) c_{2}$. Multiply both sides by $R(\beta / \mu)$ to obtain $R(\beta / \mu) u^{\prime}\left(c_{1}\right) c_{1}>R(\beta / \mu) u^{\prime}\left(c_{2}\right) c_{2}$. Using $(\beta / \mu) u^{\prime}\left(c_{1}\right)=$ $R u^{\prime}\left(c_{2}\right)=1$, this simplifies to $R c_{1}>(\beta / \mu) c_{2}$ and so $(\mu / \beta) c_{1}>c_{2} / R$.

Proof of Proposition 4. When $\eta=0$ the result is straightforward.

When $\eta=1$, note that conditions (49), (50) and (52) correspond to conditions (31)-(33). Thus, the allocation is the same as in the securities market.

Proof of Proposition 5. From (51)-(52), the first-order conditions at the Friedman rule satisfy

$$
\begin{aligned}
\pi u^{\prime}\left(c_{1}\right)+(1-\pi) \eta R u^{\prime}\left(\tilde{c}_{2}\right) & =\pi+(1-\pi) \eta \\
R u^{\prime}\left(c_{2}\right) & =1 \\
R u^{\prime}\left(\tilde{c}_{2}\right) & =1+\tilde{\zeta}
\end{aligned}
$$

There are two cases to consider: either patient agents with market access save money or they do not. Note that in both cases $c_{2}=c_{2}^{*}$ for all $\eta$.

Equilibrium with savings. If $\tilde{z}_{2}^{+} \geq 0$ does not bind, then $\tilde{\zeta}=0$ and we get $u^{\prime}\left(c_{1}\right)=$ $R u^{\prime}\left(c_{2}\right)=R u^{\prime}\left(\tilde{c}_{2}\right)=1$ implying that $c_{1}=c_{1}^{*}$ and $\tilde{c}_{2}=c_{2}=c_{2}^{*}$. All incentive constraints are satisfied since $\tilde{c}_{2}=c_{2}>c_{1}$.

From (49), strictly positive money savings requires that $c_{1}>\tilde{c}_{2} / R$. That is, we need $u^{\prime}\left(c_{1}\right) c_{1}>u^{\prime}\left(\tilde{c}_{2}\right) \tilde{c}_{2}$, which holds given [A2]. Hence, at the Friedman rule the first-best allocation is feasible, incentive-compatible and requires positive money savings.

Equilibrium without savings. If $\tilde{z}_{2}^{+} \geq 0$ binds, then $\tilde{\zeta}>0$ and $\tilde{z}_{2}^{+}=0$. From (66) and (67), we have $\tilde{c}_{2}<c_{2}$. This immediately implies that patient investors with access to 
the securities market are better off to keep their money at the bank. Accordingly, we have $c_{1}=c_{1}^{*}$ and $\tilde{c}_{2}<c_{2}=c_{2}^{*}$.

Proof of Proposition 6. Away from the Friedman rule, $\mu>\beta$, there are two cases: either patient agents with market access save money or they do not. Note that in all cases (51) implies $c_{2}=c_{2}^{*}$ for all $\mu$ and $\eta$.

Equilibrium with savings. If $\tilde{z}_{2}^{+} \geq 0$ does not bind, then $\tilde{\zeta}=0$. Conditions (51)-(52) imply

$$
R u^{\prime}\left(c_{2}\right)=R(\mu / \beta) u^{\prime}\left(\tilde{c}_{2}\right)=1
$$

implying that $\tilde{c}_{2}>c_{2}=c_{2}^{*}$. Furthermore, using (50) we obtain

$$
u^{\prime}\left(c_{1}\right)=\mu / \beta+\frac{(1-\pi) \eta(\mu / \beta-1)}{\pi} \geq \mu / \beta
$$

which implies that $c_{1}<c_{1}^{*}$. Thus, we have just shown that property (i) holds when patient investors with market access save, i.e., $c_{1}<c_{1}^{*}<c_{2}^{*}=c_{2}<\tilde{c}_{2}$. Note also that all incentive constraints are satisfied since $\tilde{c}_{2}>c_{2}>c_{1}$.

Note that $\frac{d c_{1}}{d \mu}=\frac{\pi+(1-\pi) \eta}{\beta \pi u^{\prime \prime}\left(c_{1}\right)}<0, \frac{d c_{2}}{d \mu}=0$, and $\frac{d \tilde{c}_{2}}{d \mu}=-\frac{u^{\prime}\left(\tilde{c}_{2}\right)}{\mu u^{\prime \prime}\left(\tilde{c}_{2}\right)}>0$ and so property (ii) holds when patient investors with market access save.

Also, $\frac{d c_{1}}{d \eta}=\frac{(1-\pi)(\mu / \beta-1)}{\pi u^{\prime \prime}\left(c_{1}\right)}<0$ and $\frac{d c_{2}}{d \eta}=\frac{d \tilde{c}_{2}}{d \eta}=0$ and so property (iii) holds when patient investors with market access save. Thus, higher inflation and/or higher individual participation in securities market reduces the liquidity that banks create relative to securities markets.

From (49), strictly positive money savings in equilibrium, $\tilde{z}_{2}^{+}>0$, requires that

$$
c_{1}(\mu / \beta)>\tilde{c}_{2} / R
$$

Since $\frac{d \tilde{c}_{2}}{d \mu}>0$, the right-hand side of (68) is strictly increasing in $\mu$. Given $\frac{d c_{1}}{d \mu}=\frac{\pi+(1-\pi) \eta}{\beta \pi u^{\prime \prime}\left(c_{1}\right)}$ the left-hand side of (68) can be decreasing or increasing in $\mu$ :

$$
\frac{d\left(c_{1} \mu / \beta\right)}{d \mu}=(1 / \beta)\left\{c_{1}+\frac{(\mu / \beta)[\pi+(1-\pi) \eta]}{\pi u^{\prime \prime}\left(c_{1}\right)}\right\}
$$

Accordingly, either there exists a critical value for $\mu$ denoted by $\bar{\mu}$ such that for $\mu \leq \bar{\mu}$ the patient investors with market access save and for $\mu>\bar{\mu}$ they don't save, or no such critical value exists (i.e., $\bar{\mu}=\infty$ ) and they save for all values of $\mu$. It is easy to show that $\frac{d\left(c_{1} \mu / \beta\right)}{d \mu}<0$ if $\sigma$ is sufficiently close to 1 ; as $\sigma$ increases, so does the critical value $\bar{\mu}$.

Equilibrium without savings. If $\tilde{z}_{2}^{+} \geq 0$ binds, then $\tilde{\zeta}>0$ and $\tilde{z}_{2}^{+}=0$. Condition (49) implies

$$
\tilde{c}_{2}=R(\mu / \beta) c_{1}
$$

Conditions (51)-(52) imply

$$
\begin{aligned}
\pi(\beta / \mu) u^{\prime}\left(c_{1}\right)+(1-\pi) \eta R u^{\prime}\left(\tilde{c}_{2}\right) & =\pi+(1-\pi) \eta \\
R u^{\prime}\left(c_{2}\right) & =1 \\
R u^{\prime}\left(\tilde{c}_{2}\right) & =\beta / \mu+\tilde{\zeta}
\end{aligned}
$$


The incentive-compatibility constraint $\tilde{c}_{2} \geq c_{2}$ can then be expressed as

$$
R(\mu / \beta) c_{1} \geq c_{2}
$$

From (50) and using [A3] we obtain the following expression

$$
c_{1}=\left[\frac{\pi(\beta / \mu)+(1-\pi) \eta R^{1-\sigma}(\beta / \mu)^{\sigma}}{\pi+(1-\pi) \eta}\right]^{\frac{1}{\sigma}}
$$

Clearly, $d c_{1} / d \mu<0$; with a bit of simple algebra one can show that $d c_{1} / d \eta<0$ (follows from $\left.[R(\mu / \beta)]^{1-\sigma}<1\right)$. Given $\tilde{c}_{2}=R(\mu / \beta) c_{1}, \tilde{c}_{2}$ is also strictly decreasing in $\eta$. Furthermore, we get

$$
\tilde{c}_{2}=R\left[\frac{\pi(\beta / \mu)^{1-\sigma}+(1-\pi) \eta R^{1-\sigma}}{\pi+(1-\pi) \eta}\right]^{\frac{1}{\sigma}}
$$

Thus, $\tilde{c}_{2}$ is strictly increasing in $\mu$. We have thus verified properties (ii) and (iii) when patient investors with market access do not save.

Finally, we verify the incentive-compatibility constraints, $\tilde{c}_{2} \geq c_{2} \geq c_{1}$, are satisfied. Given $c_{2}=R^{1 / \sigma}, \tilde{c}_{2}>c_{2}$ implies:

$$
\frac{\pi(\beta / \mu)^{1-\sigma}+(1-\pi) \eta R^{1-\sigma}}{\pi+(1-\pi) \eta}>R^{1-\sigma}
$$

which simplifies to $(\beta / \mu)^{1-\sigma}>R^{1-\sigma}$, which is satisfied given [A1] and [A3]. Similarly, $c_{2}>c_{1}$ implies

$$
R>\frac{\pi(\beta / \mu)+(1-\pi) \eta R^{1-\sigma}(\beta / \mu)^{\sigma}}{\pi+(1-\pi) \eta}
$$

which simplifies to

$$
\pi\left\{1-[R(\mu / \beta)]^{-1}\right\}+(1-\pi) \eta\left\{1-[R(\mu / \beta)]^{-\sigma}\right\}>0
$$

Both terms are positive given [A1] and [A3]; hence, $c_{2}>c_{1}$. Thus, property (i) holds when patient investors with market access do not save, i.e., $c_{1}<c_{1}^{*}<c_{2}^{*}=c_{2}<\tilde{c}_{2}$.

Proof of Lemma 4. If $\eta=0$ then $c_{2}<R(\mu / \beta) c_{1}$ by Lemma 3 and Proposition 4. Consider now $\eta \in(0,1)$. By (49) we have $R(\mu / \beta) c_{1} \geq \tilde{c_{2}}$ and from Proposition $6, c_{2}<\tilde{c}_{2}$. Thus, $c_{2}<R(\mu / \beta) c_{1}$.

From the bank's budget constraints, we have $(\beta / \mu) x=[\pi+(1-\pi) \eta] c_{1}$ and $R k=$ $(1-\pi)(1-\eta) c_{2}$. Thus, $(\beta / \mu)(x+k)=[\pi+(1-\pi) \eta] c_{1}+[\beta /(R \mu)](1-\pi)(1-\eta) c_{2}$. Since $c_{2}<R(\mu / \beta) c_{1}$, we get $(\beta / \mu)(x+k)<[\pi+(1-\pi) \eta] c_{1}+(1-\pi)(1-\eta) c_{1}=c_{1}$. 


\section{B General specification for money injection}

In the main body of the paper, we assume new money is injected as lump-sum transfers to workers. Here, we consider the general case. Assume a fraction $\alpha \in[0,1]$ of new money is transferred to investors. The linearity in worker's preferences implies that the relative price of goods between morning and afternoon is still being characterized by (10). Thus, $p_{t}^{m} / p_{t}^{a}=\beta / \mu$ for all $\alpha$.

The morning budget constraint for investors is now: $m_{t}=p_{t}^{m} x+\alpha T_{t}$. Since investors acquire all the cash in the morning, $m_{t}=M_{t}$, and given $T_{t}=(1-1 / \mu) M_{t}$ we obtain

$$
p_{t}^{m} x=M_{t}(\hat{\mu} / \mu)
$$

where $\hat{\mu} \equiv \mu-\alpha(\mu-1)$. Note that $\hat{\mu} \in[\mu, 1]$ for $\mu<1, \hat{\mu}=1$ for $\mu=1$ and $\hat{\mu} \in[1, \mu]$ for $\mu>1$. In addition, $\hat{\mu}$ is strictly decreasing in $\alpha$ for $\mu \neq 1$.

Afternoon real balances are given by

$$
\left(M_{t} / p_{t}^{a}\right)=(\beta / \hat{\mu}) x \text {. }
$$

Thus, morning consumption for workers is equal to $x$ and afternoon work for workers is $(\beta / \hat{\mu}) x$. So, worker's flow utility in equilibrium is $(1-\beta / \hat{\mu}) x$.

In other words, our analysis in the paper is functionally equivalent for any given $\alpha \in$ $[0,1]$. All we need to do is use $\hat{\mu}$ instead of $\mu$. To retrieve the effects on monetary policy, not the correspondence between the two variables given by $\hat{\mu} \equiv \mu-\alpha(\mu-1)$. Note that when $\alpha=1, \hat{\mu}=1$, i.e., when new money is injected only to investors, monetary policy is super-neutral. For this extreme case, all our results for $\mu=1$ apply. 